Illinois State University

ISU ReD: Research and eData

Theses and Dissertations

$4-5-2015$

\title{
Childhood Sexual Abuse And Identity Development: The Role Of Attachment And Self-Esteeem
}

Joel David Dukett

Illinois State University, jdduket@ilstu.edu

Follow this and additional works at: https://ir.library.illinoisstate.edu/etd

Part of the Family, Life Course, and Society Commons, and the Psychology Commons

\section{Recommended Citation}

Dukett, Joel David, "Childhood Sexual Abuse And Identity Development: The Role Of Attachment And SelfEsteeem" (2015). Theses and Dissertations. 391.

https://ir.library.illinoisstate.edu/etd/391

This Thesis is brought to you for free and open access by ISU ReD: Research and eData. It has been accepted for inclusion in Theses and Dissertations by an authorized administrator of ISU ReD: Research and eData. For more information, please contact ISUReD@ilstu.edu. 


\title{
CHILDHOOD SEXUAL ABUSE AND IDENTITY DEVELOPMENT: THE ROLE OF ATTACHMENT AND SELF-ESTEEEM
}

\author{
Joel D. Dukett
}

60 Pages

August 2015

The purpose of the study was to examine how childhood sexual abuse (CSA) influences identity development along with attachment and self-esteem. The participants included 208 first-year female undergraduate students from Illinois State University. Students were afforded the opportunity to receive extra credit for their participation and could enter into a random prize drawing. Participants completed a demographics questionnaire, Rosenberg Self-Esteem Scale, The Experiences in Close Relationships Questionnaire, Dimensions of Identity Development Scale, and the Hot Topics Questionnaire which assesses history of CSA. Of the participants, 145 (69.7\%) were in the non-abuse group and $63(30.3 \%)$ were in the abuse group. Results indicated that CSA was related to higher levels of attachment anxiety, attachment avoidance, and low levels of self-esteem compared to the non-abuse group. No difference was found between the abuse and non-abuse groups on levels of commitment making, identification with commitments, or ruminative exploration. Finally, poor attachment security and low levels 
of self-esteem were found to be related to lower levels of commitment making, identification with commitments, and higher levels of ruminative exploration. 
CHILDHOOD SEXUAL ABUSE AND IDENTITY DEVELOPMENT: THE ROLE OF ATTACHMENT AND SELF-ESTEEEM

JOEL D. DUKETT

A Thesis Submitted in Partial Fulfillment of the Requirements for the Degree of

MASTER OF SCIENCE

Department of Psychology

ILLINOIS STATE UNIVERISTY

2015 
CHILDHOOD SEXUAL ABUSE AND IDENTITY DEVELOPMENT:

\section{THE ROLE OF ATTACHMENT}

AND SELF-ESTEEEM

JOEL D. DUKETT

COMMITTEE MEMBERS:

Marla Reese-Weber, Chair

Corinne Zimmerman 


\section{ACKNOWLEDGMENTS}

I would like to thank my committee, Drs. Marla Reese-Weber and Corinne

Zimmerman, for their support, guidance, and collaboration throughout this process. I am a better writer, researcher, and person because of them. Thank you to Dr. Reese-Weber's research team that helped to collect and enter the data. You all made my life a lot easier. I would like to give a special thank you to Dr. Marla Reese-Weber for her consistent encouragement, motivation, and kindness through the entire project.

J. D. D. 


\section{CONTENTS}

ACKNOWLEDGMENTS $\quad$ i

CONTENTS

TABLE $\quad$ iv

\section{CHAPTER}

I. THE PROBLEM AND ITS BACKGROUND 1

II. LITERATURE REVIEW 3

Theoretical Framework 3

Betrayal 3

Stigmatization $\quad 5$

Traumatic Sexualization $\quad 8$

Powerlessness 10

$\begin{array}{ll}\text { Attachment and Self-Esteem } & 11\end{array}$

Attachment 12

Self-Esteem 16

Identity Development 18

Adolescent Identity Development 19

Childhood Sexual Abuse and Identity Development 24

$\begin{array}{ll}\text { The Current Study } & 25\end{array}$

III. RESEARCH METHODOLOGY 29

Participants $\quad 29$

Instruments $\quad 29$

Demographics Questionnaire 29

Hot Topics Questionnaire $\quad 30$ 
Experiences in Close Relationships $\quad 30$

Rosenberg Self-Esteem Scale $\quad 31$

Dimensions of Identity Development Scale 31

Procedure $\quad 32$

Ethical Considerations 33

IV. RESULTS 34

$\begin{array}{lll}\text { V. DISCUSSION } & 37\end{array}$

Limitations $\quad 42$

Future Research 43

Strengths and Contributions 44

Conclusion 45

$\begin{array}{ll}\text { REFERENCES } & 47\end{array}$

APPENDIX A: Informed Consent: Phase 1 55

APPENDIX B: Demographic Questionnaire 58

APPENDIX C: Debriefing Statement $\quad 60$ 
TABLE

Table

Page

1. Correlations between Attachment, Self-Esteem, Commitment, and Exploration

36 


\section{CHAPTER I}

\section{THE PROBLEM AND ITS BACKGROUND}

The past four decades have witnessed an increased awareness of, and research on, the effects of childhood sexual abuse (CSA). Previous studies have found approximately $20-33 \%$ of women have experienced sexual abuse prior to age 18 (Reese-Weber \& Smith, 2011; Pereda, Guilera, Forns, \& Gomez-Benito, 2009; Hall \& Hall, 2011). The effects of CSA can be seen in both short-term and long-term psychosocial outcomes (Beitchman, Zucker, Hood, DaCosta, \& Akman, 1991; Bhandari, Winter, Messer, \& Metcalfe, 2011). CSA can create dissociative symptoms (Hall \& Hall, 2011), emotional disturbances (Browne \& Finkelhor, 1986), self-esteem issues (Walker, Holman, \& Busby, 2009), and problems in interpersonal relationships (Dimitrova, Pierrehumbert, Glatz, Torrisi, Heinrichs, Halfon, \& Chouchera, 2010). Each of these factors influences the expression and formation of identity development. Hence, identity development may become disrupted by a history of CSA. The purpose of the present study is to examine how attachment and self-esteem among CSA victims is related to identity development.

The prevalence rate of CSA is influenced by its definition. Most of the research on sexual abuse indicates three types of sexual abuse: noncontact abuse, contact abuse, and intercourse or penetration. CSA research has begun to embrace other forms of abuse that previously were not included or lacked empirical investigation. For instance, 
technology has increased the means and methods of childhood exploitation, and so cyberpredator behaviors are now being included in the definition of CSA (Collin-Vezina, Daigneault, \& Hebert, 2013). The World Health Organization (2003) defines CSA as, "the involvement of a child in sexual activity that he or she does not fully comprehend, is unable to give informed consent to, or for which the child is not developmentally prepared and cannot give consent, or that violates the laws or social taboos of society" ( $\mathrm{p}$. 75). Further, CSA can be perpetrated by adults or another child who is developmentally in a position of maturity or understanding of the acts being committed. Along with evolving definitions of CSA, other factors important to individual outcomes are duration of the abuse, penetration, and aggression associated with the perpetration (Browne \& Finkelhor, 1986). Based on the World Health Organization's definition of sexual abuse, other forms of coercive acts need to be considered such as prostitution and viewing pornography, which are often excluded from CSA research. 


\section{CHAPTER II}

\section{LITERATURE REVIEW}

\section{Theoretical Framework}

Researchers and other professionals have worked to develop an agreed upon definition of CSA and formation of models describing the outcomes of CSA. Finkelhor and Browne (1985) proposed a four-factor framework to better understand the traumagenic dynamics that are created through acts of CSA. These factors are not exclusive to sexual abuse, however, when coupled with a sexual abuse experience, a unique set of circumstances are created causing a more intense traumatic experience. The model includes facets of (a) betrayal, (b) stigmatization, (c) traumatic sexualization, and (d) powerlessness. The facets have implications in the way CSA is conceptualized. Most research on CSA involves investigation of negative psychological outcomes but often ignores the importance of understanding the abuse as a phenomenological event and organizing the various outcomes on a structure that can be useful in a clinical or therapeutic setting. These dynamics provide a framework upon which to more accurately discuss the implications, mediation, and outcomes of childhood sexual abuse.

\section{Betrayal}

Betrayal refers to the child's awareness that he or she has been deceived by aindividual who has a caregiver or trusted role in the child's life (Goldsmith, Freyd, \& 
DePrince, 2012). Browne and Finkelhor (1986) suggest betrayal can be committed by anyone the child feels some level of attachment to, even if only briefly. According to the betrayal trauma theory (Freyd, 1996), the way an individual remembers a traumatic event perpetrated by a trusted person will affect the degree of betrayal experienced. The theory "predicts that the degree to which a negative event represents a betrayal by a trusted needed other will influence the way in which that events is processed and remembered" (Freyd, 2014, p. 1). This theory can be used to describe betrayal resulting from any event, but sexual abuse in childhood is the core betrayal trauma discussed in the theory (Freyd, 1996). The model places events on a two-dimensional axis with social-betrayal and terror/fear inducing facets. Social-betrayal refers to the violation of trust or loss of confidence in another person or with a social organization. Fear is generally accepted to be at the center of the trauma response and high levels of fear (i.e., terror) are often associated with negative psychological outcomes (Freyd, 2014). Using the model's dimensions, CSA involves a high level of social-betrayal and often a high level of terror or fear. The feeling of betrayal has been found to be more predictive of psychopathology (e.g., PTSD and dissociative symptoms) than self-reports of fear in a CSA sample (Deprince, 2001).

The theory posits that victims of CSA may suffer from betrayal blindness which is when the individual does not remember the abuse, or is unaware that the abuse happened. The victim may need the perpetrator, institution, or social system in which the violation occurred for survival and develop a blindness towards the abuse (Freyd, Deprince, \& Gleaves, 2007). Utilizing the same theory, Goldsmith, Freyd, and DePrince 
(2012) found significant levels of alexithymia in female undergraduate students who experienced betrayal trauma. This might indicate a dulling effect on emotional awareness of betrayal trauma leading to dysfunctional social attachments and interpersonal relationships. The theory might help to explain how betrayal can negatively influence attachment, especially in situations where the primary caregiver is the perpetrator.

Feelings of betrayal are associated with greater difficulties in creating and maintaining relationships. Victims of CSA who experience strong feelings of betrayal reported lower levels of general trust and trust in interpersonal relationships (Gobin \& Freyd, 2013). Interpersonal difficulties coupled with the feeling of betrayal have been associated with higher levels of suicidal ideation (Smith, Gamble, Cort, Ward, Conwell, \& Talbot, 2012). In a study by Spokas, Wenzel, Stirman, Brown, and Beck (2009), both male and female survivors of CSA reported feelings of hopelessness and multiple suicide attempts. More intense feelings of anger and depression were reported in CSA victims who had a high level of perceived betrayal, especially if the perpetrator was someone close to the victim such as a family member (Edwards, Freyd, Dube, Anda, \& Felitti, 2012). Betrayal could have important implications on the victim's attachment to the caregiver if the caregiver is also the perpetrator. In a study of young adult survivors of traumatic events, high levels of betrayal trauma were predictive of depression, alexithymia, anxiety, and dissociative symptoms (Goldsmith et al., 2012).

\section{Stigmatization}

Stigmatization refers to the negative feelings and meanings associated with the abuse that are communicated to the child from others and become integrated into 
cognitive schemas and beliefs about oneself. The child's personal view or understanding of the abuse acquired from family beliefs or societal perception of abuse also influence feelings about self. Stigmatization can include shame, guilt, remorse, self-blame, and decreases in self-esteem. The stigma can force the child to hide the pain because of environmental reactions, fear of the perpetrator, or considering themselves the cause of the abuse and thus it would be unreasonable to disclose without feeling shame (Finkelhor \& Browne, 1985). Also, there can be a belief that CSA causes the person to become "damaged goods" and create a feeling of stigmatization resulting in negative feelings about oneself and reduced chances of disclosure about the event. If one does disclose, the response to the disclosure of the CSA can lead to a variety of responses from others, not all of which would be supportive.

Negative reactions from others or the individual's personal reaction and perception of the CSA experience can increase the feelings of stigmatization and subsequent shame. For instance, shame as a result of sexual abuse is negatively correlated with feelings about self (Kim, Talbot, \& Cicchetti, 2009), and persistent shame about the CSA experience is related to sexual complications in adulthood and restricted sexual identity development (Feiring, Cleland, \& Simon, 2010). Stigmatization's influence on internalized feelings of self creates a higher risk for shame-proneness leading to negative external effects. In a longitudinal study of women with histories of abuse, Andrews (1995) found that CSA was predictive of bodily shame. In an exploratory analysis of the results, shame was not present before the CSA but appeared to precede the manifestation of depressive symptoms. In another study, high prevalence of shame-proneness was 
found in women with CSA histories resulting in more interpersonal conflict (Kim et al., 2009).

Shame resulting from CSA stigmatization can have lasting effects on the individual. In a study of 118 sexually abused children and adolescents, two-thirds of participants reported high levels of shame at the time of abuse discovery (Feiring \& Taska, 2005). Of those participants, about one-third reported having higher levels of shame at one-year and six-year follow up. The individuals who reported high levels of shame at one-year follow-up were more likely to experience intrusive and disturbing thoughts about the abuse event six years later (Feiring, \& Taska, 2005). Intense feelings of shame after the sexual abuse are related to poor adjustment in children and CSA victims display more symptoms of posttraumatic stress disorder in adulthood (Feiring, Taska, \& Lewis, 2002). Also, shame can lead to moods or attitudes that indiscriminately affect the individual's perception and self-esteem across different situations.

Stigmatization of CSA can develop into a sense of isolation in victims and lower self-esteem (Ratican, 1992). Negative inferences caused by shame, such as self-blame or guilt, influence the self-perception of the individual. Self-esteem refers to the beliefs, values, and feelings of worth about oneself. Self-esteem is an important factor in social development and ability to respond to stressful situations (Baumeister, Campbell, Krueger, \& Vohs, 2003). Stigmatization can be damaging to the individual's sense of worth and often results in behaviors that push people away or a reluctance to seek social support. Negative views of the self or low self-esteem can be transmitted through direct verbal abuse from an abuser or by the suppression of disclosure from a caregiver 
(Karakurt \& Silver, 2014). Many victims of CSA are reluctant to disclose the experience because of the perceived taboo of talking about the abuse and lack of disclosure can increase the feelings of stigmatization and isolation (Finkelhor \& Browne, 1985). These feelings of stigmatization can lead to increased feelings of guilt, which has been found in 25-64\% of CSA victims (Browne \& Flinkelhor, 1986). Stigmatization is increased in

dysfunctional family systems that do not support the child by attributing the blame for the abuse on the perpetrator leading to higher prevalence of self-blame (Karakurt \& Silver, 2014).

\section{Traumatic Sexualization}

Another dynamic of Finkelhor and Browne's (1985) traumagenic model, referred to as traumatic sexualization, describes the process through which a child's sexuality is inappropriately developed due to sexual abuse. The type and severity of the sexual abuse can create different kinds of traumatic sexualization. The child is often rewarded by the perpetrator for the inappropriate sexual behavior leading to the child learning to use his or her sexuality to manipulate others. Further traumatization can occur when the disturbing memories and emotions of the abuse are associated with sexual activity in the child's mind. Traumatic sexualization can lead to psychological issues such as confusion about sexual identity, negative associations with sexual activity, and difficulty establishing intimate relationships (Finkelhor, 1987).

When the child's sexual response is evoked through the abuse, the resulting traumatic sexualization creates both misconceptions about sexual behavior and a possible fear response to sexual contact. A meta-analysis of the sexual abuse literature found that 
more sexually traumatizing abuse, such as penetration, was associated with increased symptoms such as inappropriate sexual behavior and promiscuity (Kendall-Tackett, Williams, \& Finkelhor, 1993). Of the 25 studies that included sexualized behavior as a symptom of sexual abuse, $28 \%$ of participants were identified as having inappropriate sexual behaviors due to sexual abuse. In a study by Schulte-Herbrüggen et al. (2009), participants with Borderline Personality Disorder (BPD) and a history of CSA were compared to participants with a history of sexual abuse but no BPD and a control group of participants without a history of CSA or a mental health diagnosis. A self-report measure was given to assess PTSD symptoms and female sexual function such as physiological response and desire for sexual contact. Comparisons of the three groups showed that a history of CSA was found to predict sexual dysfunction (i.e., low sexual desire, sexual dissatisfaction, organic dysfunction, and pain) more than BPD alone.

Effects of traumatic sexualization experiences might be best defined on a continuum ranging from hyposexualized behaviors to hypersexualized behaviors. In another review of the sexual abuse literature, Aaron (2012) found that hypersexual behaviors or compulsive sexual behaviors, such as compulsive masturbation, dependence on pornography, and enduring promiscuity, were common in the most severely abused victims. Some of these behaviors do not fully manifest until the individual has reached adulthood, but their sexual development is inhibited or dysfunctional following the abuse. Hyposexualized behaviors are often manifested in women and include sexual dysfunctions (e.g., low physical pleasure, reduced desire, and lack of orgasm), whereas hypersexualized behaviors or increased sexual risk taking are more prevalent in men. In 
both women and men, increased sexualization of the abuse, primarily penetration, was associated with more symptoms of traumatic sexualization (Aaron, 2012).

\section{Powerlessness}

Powerlessness is created when the individual feels out of control or has a lack of autonomy. Finkelhor and Browne (1985) conceptualize powerlessness as "the process in which the child's will, desires, and sense of efficacy are continually controverted" (p. 533). The distribution of power in the offender/victim relationship or exchange is unbalanced due to threats of harm, deception, fear, or coercion by the abuser. Further, powerlessness is reinforced when the child's attempts to end the abuse are disregarded or ineffective. Powerlessness can lead to behavioral expressions such as nightmares, dissociation, and victimization (Finkelhor \& Browne, 1985). Finkelhor (1987) identified three clusters of symptoms associated with feelings of powerlessness including anxiety, inadequate coping, and aggression. Powerlessness was found to be a strong predictor of anxiety and overall psychological distress using the State-Trait Anxiety Scale (Spielberger, Gorsuch, \& Lushene, 1970). State anxiety, or how a person feels in situations where there is a perceived threat/fear, is best explained by feelings of powerlessness more than any other dynamic (Cantón-Cortés, Cortés, \& Cantón, 2012). Powerlessness causes low self-efficacy spurring from an inability to protect oneself resulting in increased avoidance behaviors and poor coping skills. Powerlessness can create a need to dominate or control others. Men, in particular, tend to internalize the experience and are more likely to express the emotional distress in the form of anger or exploiting others (Ratican, 1992). Often, feelings of inferiority lead to powerlessness 
beliefs especially in situations and relationships where a real power dynamic exists such as in cases of abuse perpetrated by church clergy or authority figure. Also, powerlessness can result in higher prevalence of posttraumatic stress disorder in CSA victims (Deprince, 2001).

\section{Attachment and Self-Esteem}

The current study focuses on two specific outcomes of CSA: attachment and selfesteem. Finkelhor and Browne's (1985) theoretical framework identifies both betrayal and stigmatization as possible dynamics resulting from the abuse. The betrayal dynamic is linked to the concept and process of attachment. In the earliest years of life, the infant forms attachment to caregivers in order to survive and receive care necessary to thrive. Attachment involves a trust between the caregiver and infant. Betrayal creates discord in the trust bond needed for appropriate infant development. According to Erikson's (1968) theory, the first stage of psychosocial development is trust vs. mistrust. In this stage, the infant is forming attachments to those who are invested in the child's wellbeing. CSA represents a betrayal resulting in insecure attachment and possible complications in later stages of psychosocial development. Although attachment begins to form in infancy, a betrayal experience such as sexual abuse in childhood or adolescence can disrupt functioning and development when the individual is in a later psychosocial stage. Previous psychosocial stages of development, such as issues surrounding trust, may be revisited. This revisiting of earlier stages is evident in the formation of psychological impairment and distress in interpersonal functioning and relationships that was not present before the CSA. 
Stigmatization caused by CSA is linked to lower self-esteem (Finklehor \& Browne, 1985). The felt stigmatization results in shame and self-blame in the individual. The components of shame and self-blame can be conceptualized as components of selfesteem. Shame is a feeling of humiliation or guilt about the abuse, often causing victims to blame themselves for allowing the abuse to happen. The developmental level of the child may influence the amount of blame they place on themselves depending on their ability to process the abuse. Young children may not have an understanding of societal attitudes toward CSA, whereas others may have knowledge of the social perception or cultural stigma of the abuse (Finkelhor \& Browne, 1985). Blame then gets assigned according to the individual's own perspective and guilt associated with the abuse. The victim is at risk of attributing other's negative reactions and their own shame about the CSA as an indication that they are damaged or less worthy of affection than other people resulting in self-esteem that suffers or fails to develop appropriately. Thus, both attachment and self-esteem are affected through CSA and will be examined in the current study.

\section{Attachment}

Attachment refers to the bond or emotional connection between an infant and a caregiver. Attachment theory owes its origins to the work of Bowlby (1969) and Ainsworth (1989). An infant's attachment to the caregiver is vital to the infant's ability to thrive and develop trust in its environment. Attachment develops from the earliest stages of life and has a strong influence on the individual's ability to cope and feel a sense of safety in the world. Attachment theory posits four attachment styles that infants display 
as a result of healthy or dysfunctional interactions with the caregiver. These different attachment styles (secure, avoidant, anxious-ambivalent, and disorganized) become a framework the infant will carry into childhood and adolescence to guide his or her understanding of interactions with others (Karakurt \& Silver, 2014).

Attachment theory is related to Erikson's (1968) psychosocial stage of trust vs. mistrust. Secure attachments reflect a trust that the child has toward the caregiver whereas insecure attachments create mistrust. Securely attached infants are more likely to trust their own ability to get their needs met and have caregivers who are responsive to those needs (Ainsworth, 1989). Children who experience inconsistent nurturing from their caregiver often display avoidant patterns of attachment learning that communication of their needs does not effectively influence the caregiver. Infants who are classified as avoidant do not appear distressed when separated from their caregiver and do not seek comfort from their caregiver when he or she is present. Anxiously attached infants show physical distress when separated from their caregiver but are ambivalent upon the return of the caregiver. Anxious attachment results in fear and emotional dysregulation in the child, often caused by a need to escalate their response to get needs met. Disorganized attachment is seen in infants with a range of behaviors that do not meet the criteria for avoidant or anxious-ambivalent attachments such as contradictory behaviors, dissociation, or fear response (Obadina, 2013). Children with hostile or neglectful caregivers often display disorganized attachment (Crittenden, 1999).

Early attachment styles provide a template for relationships later in life (Bowlby, 1969). From the research on infant and childhood attachment, Bartholomew and 
Horowitz (1991) identified four adult attachment categories (secure, preoccupied, dismissing, and fearful) based on how individuals view themselves and how they view others. Secure attachment is defined by a positive view of self and others. Individuals with secure adult attachment are comfortable with emotional closeness to others and have greater satisfaction in their relationships. Those with secure adult attachment were likely to have received consistent nurturing from their caregiver. Preoccupied attachment is representative of a person with a negative view of self but a positive view of others. These individuals seek out high levels of intimacy but also have high levels of worry about their relationships. This attachment pattern is similar to anxious attachment seen in infancy as the person worries about their needs being met consistently. Dismissive individuals have a positive view of self but a negative view of others. Dismissive attachment results in people who are independent, self-sufficient, and may tend to avoid intimate relationships. The sense of independence is comparable to avoidant attachment in childhood. In both cases, the person has learned to depend on themselves to get needs met. Fearful attachment includes those individuals who have a negative view of self and a negative view of others. This attachment is marked by ambivalence toward intimate relationships. Fearful attachment has been found in those with a CSA or other traumatic childhood experience (Liem \& Boudewyn, 1999). Similarly, disorganized attachment in infancy and childhood has been associated with abuse and neglect.

CSA has been found to predict attachment style and attachment has been identified as a mediating factor between CSA and psychological adjustment in adulthood (Roche, Runtz, \& Hunter, 1999). In a study of 324 female college students, Aspelmeier, 
Elliott, and Smith (2007) found that participants with a history of CSA reported higher level of dismissiveness, preoccupation, and fearful attachment styles. The CSA participants also reported lower levels of secure attachments measured by trust and communication with parents compared to the non-CSA group. The study found strong correlations between current attachment and self-reported parental attachment. Poor parental attachment could be representative of blame placed on parents from the child or feelings of neglect in the aftermath of the abuse. In another study of female college students, Roche et al. (1999) found that CSA was predictive of insecure attachments. The study included a non-abused group, intrafamilial abuse group, and extrafamilial abuse group. Although both groups of abused participants reported significantly more insecure attachments, those in the intrafamilial abuse group had more fearful and less dismissing attachments compared to the extrafamilial abuse group. The results indicate the importance of the relationship between victim and perpetrator on the outcome of CSA.

Attachment may be a mediating factor between CSA and psychological distress. Shapiro and Levendosky (1999) found that secure attachments mediated psychological distress in adolescents with a history of CSA. Similarly, Roche et al. (1999) identified the mediating effect of attachment. In this study, CSA did not predict psychological adjustment (i.e., depressive symptoms, dissociation, and dysfunctional sexual behavior) when attachment was controlled meaning that although CSA is predictive of attachment, attachment style can mediate the negative outcomes of CSA. These findings indicate that attachment has an important role in the development of adaptive psychological functioning following CSA. 


\section{Self-Esteem}

Self-esteem is a dynamic concept that has become popular in both psychological research and general societal discourse. Branden (1994) identified two basic foundations of self-esteem. The first is a general sense of competence and confidence that a person experiences when dealing with the struggles that daily life presents. The second is the individual's feelings of worth or the belief that they deserve to be happy. These two concepts of self-esteem do not comprehensively describe all facets of self-esteem, but rather attempt to include the major ideas of self-esteem that other nuanced aspects can be placed. Self-esteem and other behavioral or cognitive characteristics are influenced cyclically. For example, self-esteem influences the behaviors of an individual and the response of the environment to those behaviors influences self-esteem. Self-esteem is predictive of how much effort and time someone is willing to invest into a challenging task. Similarly, self-esteem correlates with other traits (e.g., extraversion, self-respect, and cooperativeness) that are predictive of successful coping and overall happiness (Branden, 1994). Individuals with CSA experiences are at a higher risk for low selfesteem resulting in reduced ability to overcome the negative effects caused by the abuse.

Research consistently shows that CSA is related to lower self-esteem. In a study of 915 high school students, sexual abuse was negatively correlated with self-esteem (Karakuş, 2012). Grayston, De Luca, and Boyes (1992) found that female survivors of CSA reported lower self-esteem than a non-abused group. In a sample of 182 college students who had previously experienced CSA, Cantón-Cortés et al., (2012) found significantly lower levels of self-esteem were reported compared to a non-abused sample. 
Low self-esteem was significantly correlated with higher levels of reported state anxiety, trait anxiety, and depression. Other studies have found that self-esteem among CSA victims is consistent over time. In a longitudinal study of 160 8-16 year old victims of CSA, abuse-specific domains of self-blame and shame were used to measure overall stigmatization of the experience and self-esteem (Feiring, Cleland, \& Simon, 2010). The study found that stigmatization of the victim at the time of discovery of the incident predicted similar stigmatization one year later. These abuse-specific domains of stigmatization were associated with negative internalizing psychological symptoms (e.g., PTSD and depression) and may lead to negative self-views and lower self-esteem.

Low self-esteem due to CSA is related to negative psychological outcomes. Individuals with low self-esteem often self-attribute the abuse and look for the reasons why the abuse happened to them (Finkelhor, 1987). This self-attribution is associated with more symptomology related to the abuse (e.g., depression, PTSD, and anxiety) whereas fewer negative attributions about the experience can be a protective factor and increase positive feelings about self (Yancey, Naufel, \& Hansen, 2013). Low self-esteem has consistently been shown to be related to higher prevalence of depression (Beichtman, Zucker, Hood, DeCosta, Akman, 1991; Ratican, 1992), making the role of self-esteem in the CSA population of particular importance. In another longitudinal study of 1,527 individuals, those with a low or declining self-esteem entering adolescence were found to have lower self-esteem in adulthood as well and presented more symptoms of depression (Steiger, Allemand, Robins, \& Fend, 2014). More to the point, Sachs-Ericsson et al. (2010) found that low self-esteem predicted more internalizing disorders in adults with a 
history of childhood abuse compared to adults without CSA.

As can be seen, both attachment and self-esteem are influenced by CSA experiences. Attachment is related to beliefs about others and self-esteem is related to beliefs about oneself. Both play an important role in the psychological outcomes of the individual. Secure attachment forms the basis of healthy relationships and relation to the environment. High self-esteem is related to positive beliefs about one's abilities and worth. Deficits in the development of either of these areas can lead to poor psychological adjustment (e.g., poor coping, dissociation, and rumination) or a mental health diagnosis such as depression or anxiety. Attachment and self-esteem can be viewed in the larger context of the individual's identity development. A person's identity is the integration of many concepts and experiences that interact with one another to form their unique perception of self or identity (Erikson, 1968). With attachment and self-esteem being intimately tied to CSA outcomes, the consequences of their development may have an important impact on identity formation. The current study examines how attachment and self-esteem among CSA victims is related to identity development.

\section{Identity Development}

The role of identity in human development over the lifespan gained significant traction after the introduction of Erikson's (1968) stages of psychosocial development. Each stage is defined by a crisis or challenge that must be negotiated but one does not need to successfully complete to move onto the subsequent stage. The early stages (trust vs. mistrust, autonomy vs. shame and doubt) are marked by dependence on others to get needs met. The individual's understanding of the world develops through interactions 
with and encouragement from others to develop a sense of autonomy. In the third and fourth stages (initiative vs. guilt, industry vs. inferiority), children develop a sense of independence through mastery of skills and cognitive growth. During adolescence, the psychosocial crisis is called identity vs. role confusion. This stage is unique in that it is the synthesis of the previous stages in preparation for the later stages. Identity develops in a social context with the individual incorporating their own beliefs with cultural influences. During the next stage, intimacy vs. isolation, identity is still an important concept as individuals are beginning to make long-term commitments in areas such as vocation and romantic relationships. Generativity vs. stagnation is the psychosocial crisis that emphasizes the need to make life meaningful. This middle adulthood stage is spent guiding the younger generation and attaining a sense of personal accomplishment. The final stage, ego integrity vs. despair, is retrospective as older adults look back on their life as successful or disappointing. Although Erikson's psychosocial stages are conceptually independent, they do not have clear-cut boundaries between them and do build on one another (Pittman et al., 2011). With this understanding, one can see that experiences during infancy and childhood influence the individual's identity exploration in adolescence and emerging adulthood, which in turn lays the foundation for adult life.

\section{Adolescent Identity Development}

Erikson posited that during adolescence individuals search for their role in the world, the beliefs and values that guide behavior, and seek to find approval in society. Identity formation is future oriented and influences the individual's goals and perception with the environment. Identity has many component parts that are integrated to form the whole of a person. These parts direct how the individual responds to external and internal 
stimuli. Identity develops through two concurring process of exploration and commitment. In Erikson's theory, adolescents must first go through a period of exploration when their values and understanding of themselves are questioned, investigated, tested, and discovered. Through exploration, adolescents then make commitments about their beliefs, which become integrated into their identity. Important to the development of identity is an unconscious wrestling of the adolescent's perception of other's judgments and his or her own self-judgments (Erikson, 1968). The process of identity formation begins with attachment in infancy, is challenged in adolescence, and determines the future direction of the person (Pittman, Keiley, Kerpelman, \& Vaughn, 2011).

Each stage has a particular psychosocial crisis that must be encountered but Erikson coined the term "identity crisis" to denote the inability of the adolescent to develop a sense of identity. An identity crisis is a natural part of maturation and does not always represent a negative pathway for development. However, during this crisis one develops a set of values that may be immature and lead to negative identity development. An identity crisis may happen more than once and a cyclical pattern does seem to emerge from the exploration and commitment to different facets of identity. The identity crisis a person experiences shapes their personality and direction of future behaviors. Erikson stated that the lack of identity development resulted in delinquency, depression, and isolation in youth (Erikson, 1968).

From Erikson's theory, Marcia (1966) conducted semi-structured interviews with research participants to gain understanding about their identity and defined four identity 
statuses that adolescents and people in general find themselves in. An individual can be at different levels of exploration and commitment at any given time and within many different domains of life such as religious beliefs, vocational goals, gender roles, sexual orientation, and intimate relationships. Achieved status is defined by a commitment as a result of a crisis period of exploration. In this case, a value has been accepted through exploration of alternative options. Identity moratorium is when a person is currently in an exploration phase but has not made a commitment yet. Foreclosed identity is when a commitment has been made but not after a period of crisis or exploration. Individuals who are foreclosed may have beliefs and values learned from their parents and have not explored other options or viewpoints. The last identity status, diffused, is defined by neither exploration nor commitment. The adolescent may feel that there are no options or lack of personal control and experience ambivalence about the particular domain.

More current research on identity development has revealed two facets of exploration (Luyckx et al. 2005; Meeus et al. 2011). Breadth is used to describe the comparison of several options before making a choice or reconsideration of a current commitment by evaluation of other alternative, and depth is defined as reflecting on the worth of an individual's current values (Klimstra, 2013; Luyckx, Goossens, \& Soenens, 2006; Meeus et al., 2011). The reason for the change in definition of exploration is that it cannot be conceptualized as a singular process. Marcia defined exploration as the process of searching for alternatives with respect to one's values and goals prior to making a commitment (Marcia, 1966). From this definition, it is clear that adolescents may evaluate areas of currently held values as well as those areas that have yet to be explored. 
As the adolescent matures and is exposed to more experiences, their beliefs and goals change.

Similarly, the commitment component of identity formation has been operationalized to include more nuanced parts of the process. Commitments are based on the "dual-cycle" identity model proposed by Luyckx et al. (2005). In this model, commitment takes place at two separate times and is reciprocal in nature. Commitmentmaking is the first cycle, which follows exploration in breadth. This commitment occurs after the adolescent has spent time searching alternatives and making a choice. This cycle of commitment measures commitment making and exploration breadth in ideological and interpersonal areas. Identification with commitment constitutes the second cycle and is encountered through exploration in depth or the reevaluation of the choice made in the commitment-making cycle. Luyckx et al. (2005) also found positive and negative correlations between the facets of exploration and commitment. Both types of exploration were positively correlated with one another and both cycles of commitment were positively correlated to one another. Exploration in breadth was negatively correlated to commitment-making possibly due to a higher level of crisis or cognitive ability that arise during adolescence. Exploration in depth and identification with commitment were positively correlated. The relationship between exploration and commitment seems to suggest that each is fluid and the relationship is reciprocal and occurring over long periods of time.

In Meeus et al.'s (2011) longitudinal study, Marcia’s original four identity statuses were found to accurately define the level of exploration and commitment in a 
large group of adolescents $(n=1,313)$. The study also confirmed the presence of a fifth identity status, searching moratorium. Although moratorium is often considered a hallmark of adolescence and represents the natural progression into adulthood, the searching moratorium status differs from the traditional conceptualization of moratorium in that the individual has very high levels of reconsideration of commitments. Searching moratorium is also defined by high commitment and exploration depth. The study used latent class growth analysis to develop identity status trajectories from data collected over a five-year period. Luyckx et al. (2008) identified a similar identity status that they labeled ruminative moratorium. Ruminative moratorium is defined by moderate levels of commitment, high levels of exploration in depth, and high levels of a new exploratory dimension called ruminative exploration. This type of exploration is characterized by "a repetitive and passive focus contributing to a feeling of hopelessness and uncontrollability" (p. 62). When individuals get stuck in a ruminative cycle without making commitments, moratorium may represent more of a diffused state of identity than the traditional view of moratorium (low levels of commitment and high levels of exploration in breadth/depth). Ruminative moratorium may represent a reconsideration of commitments due to the higher levels of commitments than what is generally conceived as moratorium.

From the research by Luyckx et al. (2008) and Schwartz et al. (2011), six identity status clusters have consistently emerged based on levels of commitment and exploration. The six clusters include Achieved (high on both commitments, moderate to high levels of exploration in breadth/depth, and low ruminative exploration), Diffused Diffusion (low on 
both commitments, moderate levels exploration in breadth/depth, and very high levels of ruminative exploration), Carefree Diffusion (low on both commitments, very low scores on exploration in breadth/depth, and moderate levels of ruminative exploration), Foreclosed (high on both commitment dimensions, low or very low exploration in breadth and ruminative exploration, and low to moderate levels of exploration in depth), Undifferentiated (moderate scores on all dimensions except a moderately high score on exploration in breadth), and Ruminative Moratorium (low to moderate on both commitments and high on each of the exploration facets, particularly on ruminative exploration). These current categories expand upon the traditional view of identity development.

\section{Childhood Sexual Abuse and Identity Development}

CSA creates complications in many domains of psychological adjustment including identity formation during the adolescent years and emerging adult years. Identity does develop over the lifespan but the greatest time of growth begins in childhood and increases during adolescent and the emerging adult years. Sexual abuse in these formative years can hinder the appropriate development of identity. Adolescence is marked by an increased ability to comprehend the meaning of the abuse and reprocessing traumas (Goodyear-Brown, 2011). This reprocessing is unique to adolescents as their cognitive processes allow for them to understand and apply meaning to the abuse. In fact, some children may not display symptoms of CSA, such as PTSD or depression, until the individual reaches adolescence (Dominguez, Nelke, \& Perry, 2002) and attempts to make sense of the abuse in the context of their overall identity development (Goodyear-Brown, 
2011). The reprocessing of CSA may increase vulnerability towards inappropriate identity formation.

An important aspect of identity development in CSA survivors is finding ways to overcome the role of the victim, which may have defined their identity for long periods of time (Draucker \& Martsolf, 2006). Often, when adolescents are confronted by the abuse, the individual will utilize an avoidant coping style in an attempt to escape reexperiencing the trauma (Goodyear-Brown, 2011). Unfortunately, this type of coping mechanism inhibits exploration of identity domains resulting in a diffused identity status. Some children may attempt to reduce the negative effects of CSA by suppressing the experience. This may be an effective strategy for the child in the short-term, but it reduces the opportunity to develop a sense of self (Goodyear-Brown, 2011). CSA experiences can induce longer periods of crisis and again reduce periods of exploration in depth and in breadth. Furthermore, it may lead to more or extended periods of ruminative exploration. In a study of female adolescents, those with a history of CSA reported more feelings of loneliness and emptiness (Brooks, 1983). These feelings can inhibit the development of the identity due to feelings of depression and inadequacy. Although there has been some correlation between CSA and poor identity development, there is a dearth of research on their relationship. The current study examines more specifically how CSA and identity formation are related.

\section{The Current Study}

Research has clearly shown that CSA is a significant issue among women with one in four women being the victim of abuse during childhood (Finkelhor, Hotaling, 
Lewis, \& Smith, 1990; Hall \& Hall, 2011; Pereda et al., 2009). CSA has been linked to many adverse psychological effects (e.g., depression, anxiety, and PTSD) and well as generally lower psychosocial functioning (e.g., less life satisfaction, lower self-esteem, and poor relationships) (Schwartz et al., 2011). In an attempt to define and better understand the outcomes of CSA, Finkelhor and Browne (1985) developed a framework of four dynamics resulting from abuse. These traumagenic dynamics (betrayal, stigmatization, traumatic sexualization, and powerlessness) help to categorize the many negative effects of CSA. The dynamics integrate many facets of the self and influence an individual's perception of the world. Some research has investigated the role of CSA outcomes on identity development, however much of the focus is on sexual identity formation (Aaron, 2012), or sexual orientation (Walker, Hernandez, \& Davey, 2012). Other facets of identity development have been neglected in the literature on CSA, such as identity exploration and commitment. Using the psychosocial stages originally developed by Erikson (1968), Marcia (1966) designated four identity statuses based on an individual's beliefs, values, and perception of self. These stages have often been used with adolescent and emerging adult populations, as they are the periods of greatest identity formation, but are rarely assessed in the CSA population. Similarly, the modern conceptualization of identity development based on the facets of identity formation (i.e., commitment making, identification with commitments, exploration in breadth and depth, and ruminative exploration) has not, to this researcher's knowledge, been investigated as to the relationship and impact of CSA.

Using the framework proposed by Finkelhor and Browne (1985) in conjunction 
with the psychosocial stages outlined by Erikson (1968), the current study investigated how outcomes of CSA influence identity development. Specifically, the dynamics of betrayal and stigmatization were examined as they are related to the psychological concepts of attachment and self-esteem respectively. Betrayal is defined as abuse by a caregiver or someone that the child is dependent on for survival. When betrayal occurs, there is a violation of trust in the child's mind leading to feelings of abandonment or lack of safety (Finkelhor \& Browne, 1985). Secure attachments are developed through feelings of safety and the child's needs being met by an attachment figure. CSA represents a betrayal of the individual's attachment, which influences adult attachment style and relationships. Stigmatization is the negative association that the child believes based on the way others react to the disclosure of abuse or the overall cultural attitude about abuse. This dynamic manifests in feelings of shame, guilt, and negative view of self. Hence, self-esteem is an important aspect of stigmatization (Cantón-Cortés et al., 2012).

Both attachment and self-esteem are important concepts within Erikson's (1968) psychosocial stages and are often explored in CSA research. They are often researched in identity research as well, particularly investigating their relationship to the changing facets of identity development (Luyckx et al., 2008; Schwartz et al., 2011). Although adequate completion of the previous stages in Erikson's model is not necessary, the fifth stage (identity vs. role confusion) and ultimately identity development, is nevertheless influenced by the experiences in the previous stages. In other words, disruptions in attachment and self-esteem due to CSA may in turn influence identity development. Yet, 
the role of identity development is frequently absent from research examining CSA. This study aimed to understand how attachment, self-esteem, and identity development are related following a CSA experience.

Based on previous findings of the association between attachment, self-esteem, and identity development; the following hypotheses were proposed.

1. Individuals with a reported history of childhood sexual abuse will have higher attachment avoidance and attachment anxiety compared to the non-abuse group.

2. Individuals with a history of childhood sexual abuse will report lower levels of self-esteem compared to the non-abuse group.

3. Individuals with lower attachment avoidance and attachment anxiety (i.e., more secure attachment) will be more likely to have higher levels of reported self-esteem. Individuals with higher attachment avoidance and attachment anxiety (i.e., more insecure attachment) will be more likely to have lower self-esteem.

4. Individuals in the child sexual abuse group will have higher levels of ruminative exploration and lower levels of commitment making and identification with commitment compared to the non-abuse group.

5. Individuals with higher attachment avoidance and anxiety (i.e., insecure attachments) will be more likely to have lower levels of commitment making, lower identification with commitments, and higher ruminative exploration.

6. Individuals with lower self-esteem will be more likely to have lower levels of commitment making, lower identification with commitment, and higher ruminative moratorium. 


\section{CHAPTER III \\ RESEARCH METHODOLOGY}

\section{Participants}

The study included 210 female undergraduate students from Illinois State University. Only incoming freshmen women between the ages of 18-22 were allowed to participate in the study. Two of the participants did not meet the criteria for the study and were removed, resulting in a final sample of 208 participants. Based on self-reports from participants, $145(69.7 \%)$ were in the non-abuse group and $63(30.3 \%)$ were in the abuse group. The mean age of the participants was $18.05(S D=.23)$ years old comprised of non-Hispanic white (78.6\%), African-American (7.6\%), Hispanic (7.1\%), and other ethnicities (6.7\%). Almost all of the participants lived in the residence halls (95.2\%), some lived with their parents (2.9\%), and some had other living situations (1.9\%). Of the participants, $66.8 \%$ had biological parents that were still married, $21.2 \%$ had biological parents that were divorced, $11.6 \%$ reported having a single parent or other family status.

\section{Instruments}

\section{Demographics Questionnaire}

Participants first completed a demographics questionnaire including questions about age, gender, sexual orientation, ethnic background, current living situation (with parents, alone, or living with someone), family composition, and parents' education. 


\section{Hot Topics Questionnaire}

This measure, originally developed as a 50-item assessment by Reese-Weber and Smith (2011), was modified to include 15 yes or no items that ask questions regarding a variety of behaviors. The behaviors include depressive symptoms and substance use. The behaviors of interest to the current study asked about sexual abuse experiences. The shortened version of the questionnaire included five items focusing on nonconsensual sexual experiences. This measure was used to classify individuals with and without experiences of childhood sexual abuse. The critical items of importance include: (a) Someone has sexually touched me in ways that made me feel uncomfortable, (b) Before the age of 16 , I had a sexual experience with an individual five or more years older than myself (any sexual activity involving physical contact), (c) Another person has coerced me to engage in sexual activity (intercourse, oral sex, anal sex, petting/fondling), (d) I have engaged in sexual activity (intercourse, oral/anal sex, petting) when I didn't want to because someone threatened to use physical force, and (e) I have been sexually assaulted. Answering yes to any of the five items led to assignment in the abuse group. Answering no to all five items led to assignment in the non-abuse group.

\section{Experiences in Close Relationships}

The Experiences in Close Relationships (ECR; Brennan, Clark, \& Shaver, 1998) is a pen-and-paper assessment used to measure adult attachment style. The ECR consist of 36 items rated on a 7-point Likert scale with responses ranging from (1) disagree strongly to (7) strongly agree. Items on the assessment measure two subscales: attachment anxiety (i.e., the extent to which individuals feels secure or insecure about the 
availability of their partner) and attachment avoidance (i.e., the degree to which an individual is willing to get close to another or the feeling of discomfort arising from closeness to others). The subscales are scored and totaled to indicate levels of anxiety and avoidance. Representative items for the anxiety and avoidance subscales, respectively, include "I often worry my partner doesn't love me" and "It helps to turn to my romantic partner in times of need." Coefficient alphas ranged from .87 to .96 for avoidance and .84 to .94 for anxiety (Brennan, Clark, \& Shaver, 1998).

\section{Rosenberg Self-Esteem Scale}

Participants completed the Rosenberg Self-Esteem Scale (RSE; Rosenberg, 1965) to assess individual levels of global self-esteem. The RSE contains 10 items and is rated on a 4-point Likert scale from (1) Strongly Disagree to (4) Strongly Agree. Test-retest reliability over two weeks was .85 and correlations with related measures have ranges from .56-.83 (Silber \& Tippett, 1965).

\section{Dimensions of Identity Development Scale}

Participants completed the Dimensions of Identity Development Scale (DIDS, Luyckx et al., 2008). The DIDS contains 25 items and is rated on a 5-point Likert scale ranging from (0) Strongly Disagree to (4) Strongly Agree. The scale was developed to measure five dimensions of identity formation including (a) commitment-making, (b) identification with commitments, (c) exploration in breadth, (d) exploration in depth, and (e) ruminative exploration. Luyckx et al. (2008) and Schwartz et al. (2011) report strong internal consistency reliability with coefficient alphas ranging from .81 to .93. Representative items include, "I know what I want to do with my future" (commitment- 
making) and "It is hard for me to stop thinking about the direction I want to follow in life" (ruminative exploration).

\section{Procedure}

The study recruited participants using the SONA system and brief announcements were made by research assistants in classes likely to have large numbers of freshman students outside of the Psychology Department (i.e., ENG 100, COM 100). Instructors for the classes were contacted prior to making announcements in their classrooms. The requirements for individuals to participate were: (a) they must be a woman, (b) between the age of 18-22 years old, and (c) first-time, incoming freshman. The participants were told that the study consisted of completing pen-and-paper questionnaires that would take approximately 30 minutes to complete. Announcement and flyers also provided times and locations of the study.

Participants convened in large groups when completing the assessments.

Participants signed an informed consent document and were given a survey to complete. The survey included the demographic questionnaire, Hot Topics, attachment, self-esteem, and identity development questionnaires. After completing the questionnaires, participants placed them into a manila envelope and placed the envelope into a box at the front of the room. Once the questionnaires were collected, the participants were given a debriefing statement that contained information about Illinois State Counseling Services and the local crisis hotline. The researchers' contact information was also provided. Students either received extra credit for their participation or were entered into a random prize drawing for \$25 Amazon gift cards. 


\section{Ethical Considerations}

The participants were seated with at least one desk in between them to reduce the likelihood that someone could see their answers. Once surveys were completed, participants placed them into envelopes to ensure that the responses remain confidential from other participants and the research team. Participants completed a questionnaire to determine if they had been sexually abused but only Dr. Reese-Weber knew which participants were in the abuse group and the non-abuse group. Research assistants had access to the data; however, the data did not include any identifying information. The data was stored securely in Dr. Reese-Weber's research laboratory. If a participant became upset or experienced emotional distress while completing the questionnaires, research assistants were trained to remind the individual that she could withdraw at any time from the study. Also, research assistants were trained to take the participant to the student counseling center if necessary. There were no incidents of participants becoming emotional upset throughout the data collection process. Participants were provided a debriefing statement which contained information about the study, the number of the student counseling center, and the number to a local crisis hotline. 


\section{CHAPTER IV}

\section{RESULTS}

The first hypothesis, individuals with a reported history of childhood sexual abuse will have higher attachment avoidance and attachment anxiety compared to the nonabuse group, was tested by conducting an independent samples $t$-test. The participants who experienced childhood sexual abuse $(M=22.96, S D=2.85)$ reported significantly higher levels of attachment anxiety than those in the non-abuse group $(M=20.38, S D=$ 1.69), $t(206)=-3.78, p<.01$. Attachment avoidance approached a significant difference between the non-abuse and abuse group $(M=20.92, S D=2.60), t(206)=-1.95, p=.053$.

Similarly, the second hypothesis stating that there would be a difference in selfesteem between the abuse and non-abuse group was conducted using an independent samples $t$-test. There was a significant difference between the non-abuse group $(M=$ $31.56, S D=5.30)$ and abuse group $(M=29.29, S D=5.72)$ on reported levels of selfesteem $t(206)=2.47, p<.01$, such that the abuse group had lower self-esteem than the non-abuse group.

The third hypothesis, that attachment style (i.e., both anxiety and avoidance) would be inversely/negatively related to self-esteem regardless of CSA was also supported. . Self-esteem was negatively correlated with attachment anxiety $r(206)=-.58$, $p<.01$ and attachment avoidance $r(206)=-.42, p<.01$ indicating that lower levels of 
self-esteem are related to higher levels of insecure attachments. The fourth hypothesis predicted that the abuse group would have higher levels of ruminative exploration, lower levels of commitment making, and lower levels of identification with commitment compared to the non-abuse groups. There was no significant difference between the nonabuse $(M=8.62, S D=4.32)$ and abuse groupss $(M=9.08, S D=4.82)$ on level of ruminative exploration $t(205)=-.71, p=.48$. The differences between the non-abuse $(M$ $=15.55, S D=3.72)$ and abuse $(M=15.66, S D=3.47)$ groups on levels of commitment making was also not significant, $t(205)=-.16, p=.87$. Finally, the non-abuse $(M=15.90$, $S D=3.85)$ and abuse $(M=15.52, S D=3.53)$ group also did not differ on identification with commitment $t(205)=.78, p=.55$. These results indicate that women with and without a history of CSA do not differ with respect to levels of commitment making, identification with commitment, or levels of ruminative exploration regarding identity development. Hypothesis four was not supported.

The fifth hypothesis examined the relationship between attachment and commitment making, identification with commitment, and ruminative exploration. The hypothesis stated that individuals with higher attachment anxiety and attachment avoidance would have lower levels of commitment making and identification with commitment, regardless of CSA status. Also, attachment anxiety and attachment avoidance were predicted to be related to higher levels of ruminative exploration. Bivariate correlations were conducted to test the hypothesis (See Table 1). The results indicated that attachment anxiety was negatively correlated with both commitment making and identification with commitment. Attachment anxiety was positively related to 
ruminative exploration making. Attachment avoidance was found to be negatively correlated with levels of commitment making and with identification with commitment. As with attachment anxiety, attachment avoidance was positively correlated with ruminative exploration. The results of these analyses are presented in Table 1.

The sixth hypothesis examined the relationship between self-esteem and levels of commitment making, identification with commitment, and ruminative exploration. The results indicate that lower levels of self-esteem are related to lower levels of both commitment making and identification with commitments, and higher levels of ruminative exploration, supporting hypothesis six. The results of these analyses are presented in Table 1.

Table 1

Correlations between Attachment, Self-Esteem, Commitment, and Exploration

\begin{tabular}{|c|c|c|c|c|c|c|}
\hline & $\begin{array}{l}\text { Attachment } \\
\text { Anxiety }\end{array}$ & $\begin{array}{l}\text { Attachment } \\
\text { Avoidance }\end{array}$ & $\begin{array}{c}\text { Self- } \\
\text { Esteem }\end{array}$ & $\begin{array}{l}\text { Commitment } \\
\text { Making }\end{array}$ & $\begin{array}{l}\text { Commitment } \\
\text { Identification }\end{array}$ & $\begin{array}{l}\text { Ruminative } \\
\text { Exploration }\end{array}$ \\
\hline $\begin{array}{c}\text { Attachment } \\
\text { Anxiety }\end{array}$ & & $.543^{* *}$ & $\begin{array}{r}.588^{*} \\
*\end{array}$ & $-.209^{* *}$ & $-.227^{* *}$ & $.288^{* *}$ \\
\hline $\begin{array}{l}\text { Attachment } \\
\text { Avoidance }\end{array}$ & $.543^{* *}$ & & $.438^{*}$ & $-.229^{* *}$ & $-.332^{* *}$ & $.241^{* *}$ \\
\hline Self-Esteem & $-.588^{* *}$ & $-.438^{* *}$ & & $.267^{* *}$ & $.374^{* *}$ & $-.341^{* *}$ \\
\hline $\begin{array}{c}\text { Commitment } \\
\text { Making } \\
\end{array}$ & $-.209^{* *}$ & $-.229^{* *}$ & $\begin{array}{r}.267^{*} \\
*\end{array}$ & & $.790^{* *}$ & $-.603^{* *}$ \\
\hline $\begin{array}{l}\text { Commitment } \\
\text { Identification }\end{array}$ & $-.227^{* *}$ & $-.332^{* *}$ & $.374^{*}$ & $.790^{* *}$ & & $-.518^{* *}$ \\
\hline $\begin{array}{l}\text { Rumination } \\
\text { Exploration }\end{array}$ & $.288^{* *}$ & $.241^{* *}$ & $.341^{*}$ & $-.603^{* *}$ & $-.518^{* *}$ & \\
\hline
\end{tabular}




\section{CHAPTER V \\ DISCUSSION}

Understanding the impact of CSA can be complex due to the many factors involved, but recognizing its outcomes can help to inform prevention and intervention. The large number of individuals who are victims of CSA make the negative outcomes such as stigmatization, betrayal trauma, and psychopathology all the more significant and relevant. In the current study, one third of the sample reported experience with CSA. The current study investigated how CSA may influence attachment, self-esteem, and identity development. Based on the traumagenic dynamics perspective (Finkelhor \& Browne, 1985), attachment and self-esteem were investigated as they related to betrayal and stigmatization. In addition, a contemporary conceptualization of identity (Luyckx et al., 2008) was used to examine how CSA may be related to the facets of identity development. The results indicated that high levels of attachment avoidance and anxiety were correlated with lower levels of self-esteem and that individuals with a history of CSA were more likely to have both poor attachment and lower self-esteem. Although this study found poorer attachment and lower self-esteem were related to less developed identities, elements of identity development were not different for those with and without a history of CSA.

Support for hypothesis one was found. Female college freshman with a history of 
CSA reported having more attachment anxiety and attachment avoidance than those without a history of CSA. Similarly, previous research found that CSA was related to dismissiveness and fearful attachment styles in female college students (Aspelmeier, Elliott, \& Smith, 2007). The connection between CSA and attachment is particularly important given that attachment has been found to be a mediator between CSA and psychological distress. Specifically, positive attachment style (i.e., those low in anxiety and avoidance) has been found to mediate the relationships between CSA and negative outcomes such as depression and dissociation (Roche et al., 1999). This finding supports the view that individuals with a trauma history have more fearful attachment styles in adulthood (Bartholomew \& Horowitz, 1991), which have been associated with traumatic childhood experiences (Liem \& Boudewyn, 1999). Individuals displaying insecure or fearful attachment style as a result of CSA have more negative views about themselves and others causing reduced or maladaptive coping skills. Taken together, individuals with a history of CSA may have poor attachment that in turn could lead to poor psychological adjustment.

Hypothesis two was also supported. Participants who reported a history of CSA had lower levels of self-esteem than participants who had no history of abuse. This result is consistent with previous research that also found childhood sexual abuse was an important determinant of self-esteem (Cantón-Cortés et al., 2012; Karakuş, 2012). Also, self-esteem has been found to be significantly correlated with self-blame for the sexual abuse (Cantón-Cortés et al., 2012). This self-blame is related to the concept of stigmatization in that the individual places responsibility for the abuse on themselves, 
often leading to feelings of shame or guilt (Finkelhor \& Browne, 1984). Stigmatization occurs in varying degrees based on the child's environment and often causes feelings of being different or damaged (Finkelhor \& Browne, 1984). Stigmatization manifests in reduced searching for support and feelings of isolation. As shown through previous and current research, a history of CSA is associated with stigmatization leading to lower selfesteem, which is related to negative psychological consequences.

Hypothesis three, which predicted that high levels of attachment anxiety and attachment avoidance were related to lower levels of self-esteem, was also supported. This relationship holds, regardless of one's CSA status. The results do not indicate the direction of influence, that is whether attachment influences self-esteem or vice versa (or whether an additional variable or variables mediate this relationship). However, when the findings are viewed within the framework of Erikson's (1968) psychosocial stages, secure attachments in childhood may be predictive of higher self-esteem later. That is, the first stages present attachment challenges. These early stages of trust vs. mistrust and autonomy vs. shame/doubt include the period of time when attachment is forming. These early stages build on one another making successful navigation through them important for success in later stages. The initiative vs. guilt and industry vs. inferiority stages are associated with self-esteem development (Erikson, 1968). Children in these stages are exploring the world, developing competencies, and uncovering their skills. Experiences at any of these intervals can influence subsequent psychological growth such that trauma in the early stages during attachment development can negatively influence self-esteem. Other studies have shown this progression as attachment styles influenced the levels of 
personal and collective self-esteem as well as importance placed on self-esteem (Simsek, 2013). Individuals with a secure attachment style have an integrated self-esteem naturally derived from their attachment and place less importance on self-esteem development due to it already being incorporated in them. Those with insecure attachment may focus on increasing self-esteem to a greater extent because it has not developed appropriately as a consequence of their attachment insecurity (Simsek, 2013). The relationship found between attachment and self-esteem could be indicative of maturation through childhood into adolescence such as the move from egocentricity to a period of self-identity achievement through the lifespan (O'Connor \& Nikolic, 1990).

Contrary to hypothesis four, the CSA group did not differ significantly from the non-abuse group on commitment making, identification with commitment, or ruminative exploration. This finding could suggest that CSA does not directly influence identity development, but may affect other factors that have a more direct influence on identity development. For example, the results found support for the hypotheses that attachment and self-esteem would be different between abuse and non-abuse group in their identity development. There is little prior research that has investigated the role of CSA on identity development. Those studies that do examine that relationship tend to focus on sexual identity rather than the broader concept of identity tested in this study. The findings of this research indicate that CSA does not directly inform identity development, but may indirectly do so through other mechanisms or constructs not assessed here.

Support for hypothesis five was found. Higher levels of attachment anxiety and attachment avoidance were related to lower levels of commitment making, lower 
identification with commitment, and higher levels of ruminative exploration, regardless of CSA status. The current research supports prior studies investigating the role of attachment style on the level of commitment making and identification with commitments. Attachment anxiety and avoidance has been found to be related to lower commitments and exploration often resulting in diffused identity status. Attachment avoidance, in particular, has been found to be a significant predictor of poor identity commitment (Kerpelman, Pittman, Saint-Eloi Cadely, Tuggle, Harrell-Levy, \& AdlerBaeder, 2012). Ratner (2014) found that attachment to one's maternal figure was related to style of commitment making. A supportive parenting style and responsiveness to the needs of the child were related to higher levels of identity exploration and commitments. Positive peer attachments have also been linked to commitment making and identity development (Nawaz, 2011). Less has been researched in regard to the relationship between attachment style and ruminative exploration. In one study, insecure attachment between adolescents and their parents was associated with depression and rumination (Ruijten, Roelofs, \& Rood, 2011). Rumination, which is defined as a maladaptive focus on symptoms of distress from past experiences, is related to anxiety and negative emotional experiences that individuals may try to avoid. The results from the current study support prior research and the relationship between anxious and avoidant attachment styles with identity development.

Finally, hypothesis six was supported. Low levels of self-esteem were related to lower levels of commitment making, lower identification with commitments, and higher levels of ruminative exploration, regardless of CSA. The current results are consistent 
with previous findings linking self-esteem and facets of identity development. Schwartz et al. (2011) found higher levels of self-esteem were correlated with achieved and foreclosed identity statuses. These identity statuses are defined by high levels of commitment making and identification with commitments. Also, they found that low self-esteem was associated with higher ruminative exploration. Self-esteem has an important impact on one's ability to explore aspects of identity (Crocetti, Luyckx, Scrignaro, \& Sica, 2011) and in turn the ability to commit to those beliefs and values. The current research found low self-esteem was correlated to higher levels of ruminative exploration which is related to higher levels of depression (Schwartz et al., 2011). This is evident in the lack of commitment making and identification with commitments. Lower levels of self-esteem result in fewer internal resources and poor self-concept leading to a deferment of identity formation and overall identity formation.

\section{Limitations}

The present results should be interpreted with the following limitations in mind. First, the sample was not randomly selected as the participants entered on their own volition in exchange for extra credit or the chance to win Amazon gift cards. Furthermore, information about the individuals who chose to not participate is unknown, thus the representativeness of the sample is not known. Also, over 78 percent identified as non-Hispanic Caucasian meaning the results may not be generalizable to other minority populations. Second, the study was comprised of only college students. Previous research has found that college students may engage in more ruminative thinking than individuals who enter the workforce (Luyckx et al., 2008). The results may then be 
different if the study was to include a non-college sample. Third, the study used only selfreport measures completed at the beginning of the first semester of college. The study would have benefited from assessment of the same measures at more than one point in time to assess if change had occurred or if the responses may have been in reaction to the transition into college. Utilizing a longitudinal design would give more support for the reliability of the results. Finally, self-report measures can be influenced by several factors such as the participant's mood, social desirability, or confirmation bias.

\section{Future Research}

Despite the limitations of the study, it does begin to link the concepts of childhood sexual abuse and identity development where such investigation has been neglected. This study offers new information on important developmental outcomes resulting from such abuse by examining the connection between the concepts of attachment and self-esteem. Future research could continue to build on this research in several ways. First, future research would benefit from investigating a more diverse population through inclusion of both ethnically diverse and non-college student populations. Having more generalizable results would allow researchers to draw out clinical implications for non-college populations. Research on more diverse samples would allow us to understand other factors that may make particular populations more at risk than others. Second, future studies could investigate the relationship between CSA and identity development longitudinally. A longitudinal approach would be useful for determining change in exploration and commitments as well as increasing understanding of identity formation during critical developmental stages. Third, additional variables 
could be investigated along with those included in this study. For example, other studies have investigated the relationship of depression and anxiety with both identity development and CSA. Additionally, mediation and moderation models could be developed with the goal of identifying how the varying psychological factors interact to influence the outcomes of CSA. Finally, other traumagenic factors and related psychological concepts could be explored as to their relationship with identity development. This would give a better understanding about how negative outcomes of CSA occur from a developmental approach. Ultimately, due to the dearth of research on the relationship between CSA and identity development, many additional concepts need to be investigated to increase understanding of how negative outcomes develop and become integrated into the victim's sense of self.

\section{Strengths and Contributions}

There are several strengths to this study. This research was the first to examine the relationship between childhood sexual abuse and levels of commitment and rumination. Previous research has investigated CSA and other aspects of identity development, usually sexual identity development. Identity research has only recently provided a new framework of identity formation based on expanded facets of commitment and exploration. Utilizing a developmental conceptualization as first outlined by Erikson's (1968) psychosocial stages but with the use of contemporary identity measures, this study investigated whether CSA experiences resulted in different adaptive and maladaptive exploratory/commitment processes. Also, the present research adds to the growing number of studies examining identity formation in an emerging adult 
population, especially with regard to the changing core dimensions of identity. The study contributes to the current knowledge on the relationships among attachment, self-esteem, CSA, and identity development.

\section{Conclusion}

The present study examined the relationship between childhood sexual abuse, psychological outcomes measured through attachment and self-esteem, and identity development. Understanding attachment's influence on outcomes of CSA and its relationship to identity development can have important clinical implications. Attachment has been shown to be a mediator of poor psychological adjustment and psychopathology resulting from CSA (Aspelmeier et al., 2007). In fact, many therapeutic modalities incorporate attachment theory such as Trust Based Relational Intervention (Purvis et al., 2007), family systems therapy (Schultz, 1984), and Theraplay (Booth \& Jernberg, 2010). Attachment and the victim's sense of safety are vital to appropriate processing of the trauma and identity consolidation. Similar to attachment, understanding self-esteem can be important for informing clinical interventions. Increasing one's level of self-esteem is important as a protective factor for reducing stigmatization (Cantón-Cortés et al., 2012), and it is related to active coping strategies that reduce negative psychological symptoms associated with CSA such as anxiety and depression (Eisenbarth, 2012). Interventions

aimed at increasing self-esteem have been successfully integrated in a cost effective way at university counseling centers and could be utilized in other settings as well.

Identity, in general, is important from a theoretical and practical point of view. Understanding the mechanism through which identity develops can be important when 
viewed through the lens of CSA because abuse causes many negative public health issues, one of which is a cycle of CSA perpetration (Andrews et al., 2004). Thus, it is ever important to understand the factors that lead to negative outcomes following a CSA experience, what factors can help mediate those outcomes, and what preventative measures can be taken. CSA alone was not related to levels of commitment making or ruminative exploration. However, both attachment and self-esteem were negatively influenced by a history of CSA and were correlated to commitment making and ruminative exploration. Future research should continue to look at the relationship between the factors investigated in the current study to find possible mediating influences of attachment and self-esteem on identity development among those with a history of childhood sexual abuse. 


\section{REFERENCES}

Aaron, M. (2012). The pathways of problematic sexual behavior: A literature review of factors affecting adult sexual behavior in survivors of childhood sexual abuse. Sexual Addiction \& Compulsivity, 19(3), 199-218. doi:10.1080/10720162.2012.690678

Ainsworth, M. D. S. (1989). Attachments beyond infancy, American Psychologist, 44, 709-716.

Andrews, B. (1995). Bodily shame as a mediator between abusive experiences and depression. Journal Of Abnormal Psychology,104(2), 277-285.

Andrews, G, Corry, J, Slade, T, Issakidis, C, and Swanston, H. Child sexual abuse. Comparative Quantification of Health Risks. WHO, Geneva; 2004

Aspelmeier, J. E., Elliott, A. N., \& Smith, C. H. (2007). Childhood sexual abuse, attachment, and trauma symptoms in college females: The moderating role of attachment. Child Abuse and Neglect, 31, 549-566.

doi:10.1016/j.chiabu.2006.12.002

Branden, N. (1994). The six pillars of self-esteem. New York, NY: Bantam, 1994

Beichtman, Zucker, Hood, DeCosta, Akman, (1991). A review of the short-term effects of childhood sexual abuse. Child Abuse and Neglect, 15, 537-556.

Baumeister, R. F., Campbell, J. D., Krueger, J. I., \& Vohs, K. D. (2003). Does high selfesteem cause better performance, interpersonal success, happiness, or health lifestyles?. Psychological Science In The Public Interest, 4(1), 1-44. doi:10.1111/1529-1006.01431

Bhandari, S., Winter, D., Messer, D., Metcalfe, C. (2011). Family characteristics and long-term effects of childhood sexual abuse. British Journal of Clinical Psychology. 50, 435-451.

Booth, P. B., \& Jernberg, A. M. (2010). Theraplay: Helping parents and children build better relationships through attachment-based play. San Francisco, CA: JosseyBass 
Brown, J. D. (2010). High self-esteem buffers negative feedback: Once more with feeling. Cognition \& Emotion, 24(8), 1389-1404.

doi:10.1080/02699930903504405

Browne, A., \& Finkelhor, D. (1986). Impact of sexual abuse: A review of the literature. Psychological Bulletin, 99, 66-77.

Bowlby, J. (1969). Attachment and loss, vol. 1: Attachment. New York, NY: Basic Books.

Cantón-Cortés, D., Cortés, M., \& Cantón, J. (2012). The role of traumagenic dynamics on the psychological adjustment of survivors of child sexual abuse. European Journal Of Developmental Psychology, 9(6), 665-680.

doi:10.1080/17405629.2012.660789

Crittenden, P. (1999). Danger and development: The organization of self-protective strategies. Monographs Of The Society For Research In Child Development, 64(3), 145

Crocetti, E., Luyckx, K., Scrignaro, M., \& Sica, L. S. (2011). Identity formation in Italian emerging adults: A cluster-analytic approach and associations with psychosocial functioning. European Journal of Developmental Psychology, 8(5), 558-572. doi:10.1080/17405629.2011.576858

Del Castillo, D., \& Wright, M. (2009). The perils and possibilities in disclosing childhood sexual abuse to a romantic partner. Journal Of Child Sexual Abuse, 18(4), 386-404.

DePrince, A. P. (2001). Trauma and posttraumatic responses: An examination of fear and betrayal (Doctoral dissertation, University of Oregon). Retrieved from http://search.proquest.com/docview/304715729? accountid=11578. (304715729).

Dimitrova, N., Pierrehumbert, B., Glatz, N., Torrisi, R., Heinrichs, M., Halfon, O., \& Chouchena, O. (2010). Closeness in relationships as a mediator between sexual abuse in childhood or adolescence and psychopathological outcome in adulthood. Clinical Psychology \& Psychotherapy, 17(3), 183-195.

Draucker, C. B. \& Martsolf, D. S. (2006). Counseling survivors of childhood sexual abuse. Thousand Oaks, CA: Sage Publication.

Edwards, V. J., Freyd, J. J., Dube, S. R., Anda, R. F., \& Felitti, V. J. (2012). Health outcomes by closeness of sexual abuse perpetrator: A test of betrayal trauma theory. Journal of Aggression, Maltreatment \& Trauma, 21(2), 133-148. doi:10.1080/10926771.2012.648100 
Eisenbarth, C. (2012). Does self-esteem moderate the relations among perceived stress, coping, and depression?. College Student Journal, 46(1), 149-157.

Erikson, E. H. (1968). Identity, youth, and crisis. New York, NY: W. W. Norton.

Feiring, C., Cleland, C. M., \& Simon, V. A. (2010). Abuse-specific self-schemas and self-functioning: A prospective study of sexually abused youth. Journal of Clinical Child \& Adolescent Psychology, 39(1), 35-50. doi:10.1080/15374410903401112

Feiring, C., \& Taska, L. (2005). The persistence of shame following sexual abuse: a longitudinal look at risk and recovery. Child Maltreatment, 10(4), 337-349.

Feiring, C., Taska, L., \& Lewis, M. (2002). Adjustment following sexual abuse discovery: The role of shame and attributional style. Developmental Psychology, 38(1), 79-92.

Finkelhor, D. (1987). The trauma of sexual abuse: Two models. Journal of Interpersonal Violence, 2(4), 348-366.

Finkelhor, D., \& Brown, A. (1985). The traumatic impact of childhood sexual abuse: A conceptualization. American Journal of Orthopsychiatry, 66, 530-541.

Freshwater, K., Leach, C., \& Aldridge, J. (2001). Personal constructs, childhood sexual abuse and revictimization. British Journal Of Medical Psychology, 74(3), 379397.

Freyd, J. J. (1996) Betrayal trauma: The logic of forgetting childhood abuse. Cambridge, MA.: Harvard University Press.

Freyd, J.J. (2014). What is a Betrayal Trauma? What is Betrayal Trauma Theory? Retrieved [04/28/2014] from http://pages.uoregon.edu/dynamic/jjf/defineBT.html.

Freyd, J. J., Deprince, A. P., \& Gleaves, D. H. (2007). The state of betrayal trauma theory: Reply to McNally - Conceptual issues, and future directions. Memory, 15(3), 295-311. doi:10.1080/09658210701256514

Gobin, R. L., \& Freyd, J. J. (2013). The impact of betrayal trauma on the tendency to trust. Psychological Trauma: Theory, Research, Practice, And Policy, doi:10.1037/a0032452

Goldsmith, R. E., Freyd, J. J., \& DePrince, A. P. (2012). Betrayal trauma: Associations with psychological and physical symptoms in young adults. Journal of Interpersonal Violence, 27(3), 547. doi:10.1177/0886260511421672 
Goodyear-Brown, P. (2011). Treatment considerations with sexually traumatized adolescents. Handbook of Child Sexual Abuse, 447.

doi:10.1002/9781118094822.ch20

Grayston, A., De Luca, R., \& Boyes, D. (1992). Self-esteem, anxiety, and loneliness in preadolescent girls who have experienced sexual abuse. Child Psychiatry and Human Development, 22(4), 277-286.

Hall, M., \& Hall, J. (2011). The long-term effects of childhood sexual abuse: Counseling implications. Retrieved from http://counselingoutfitters.com

Hazzard, A. (1993). Trauma-related beliefs as mediators of sexual abuse impact in adult women survivors: A pilot study. Journal of Child Sexual Abuse, 2, 55-69.

Hopper, J. (2012). Sexual abuse of males: Prevalence, possible lasting effects, and resources. Retrieved from http://www.jimhopper.com

Kallstrom-Fuqua, A., Weston, R., \& Marshall, L. (2004). Childhood and adolescent sexual abuse of community women: mediated effects on psychological distress and social relationships. Journal Of Consulting And Clinical Psychology, 72(6), 980-992.

Karakurt, G., \& Silver, K. E. (2014). Therapy for childhood sexual abuse survivors using attachment and family systems theory orientations. American Journal of Family Therapy, 42(1), 79-91. doi:10.1080/01926187.2013.772872

Karakuş, Ö. (2012). Relation between childhood abuse and self-esteem in adolescence. International Journal Of Human Sciences, 9(2), 753-763.

Kendall-Tackett, K. A., Williams, L. M., \& Finkelhor, D. (1993). Impact of sexual abuse on children: A review and synthesis of recent empirical studies. Psychological Bulletin, 113(1), 164-180. doi:10.1037/0033-2909.113.1.164

Kerpelman, J. L., Pittman, J. F., Saint-Eloi Cadely, H., Tuggle, F. J., Harrell-Levy, M. K., \& Adler-Baeder, F. M. (2012). Identity and intimacy during adolescence: Connections among identity styles, romantic attachment and identity commitment. Journal Of Adolescence, 35, 1427-1439. doi:10.1016/j.adolescence.2012.03.008

Kim, J., Talbot, N. L., \& Cicchetti, D. (2009). Childhood abuse and current interpersonal conflict: The role of shame. Child Abuse \& Neglect: The International Journal, 33(6), 362-371.

Klimstra, T. (2013). Adolescent personality development and identity formation. Child Developmetn Perspectives, 7(2), 80-84, DOI: 10.1111/cdep.12017 
Liem, J., \& Boudewyn, A. (1999). Contextualizing the effects of childhood sexual abuse on adult self- and social functioning: An attachment theory perspective. Child Abuse \& Neglect, 23(11), 1141-1157.

Lisak, D. (2014). The next wave: Male survivors of childhood sexual abuse. Sexual Assault Report, 17(4), 49-59.

Luyckx, K., Goossens, L., Soenens, B., Beyers, W., \& Vansteenkiste, M. (2005). Identity statuses based on 4 rather than 2 identity dimensions: Extending and refining Marcia's paradigm. Journal Of Youth And Adolescence, 34(6), 605-618.

Luyckx, K., Goossens, L., \& Soenens, B. (2006). A developmental contextual perspective on identity construction in emerging adulthood: Change dynamics in commitment formation and commitment evaluation. Developmental Psychology, 42(2), 366380 .

Luyckx, K., Schwartz, S., Berzonsky, M., Soenens, B., Vansteenkiste, M., Smits, I., \& Goossens, L. (2008). Capturing ruminative exploration: Extending the fourdimensional model of identity formation in late adolescence. Journal Of Research In Personality, 42(1), 58-82.

Marcia, J. (1966). Development and validation of ego-identity status. Journal Of Personality And Social Psychology, 3(5), 551-558.

Meeus, W., Schoot, R., Keijsers, L., \& Branje, S. (2012). Identity statuses as developmental trajectories: A five-wave longitudinal study in early-to-middle and middle-to-late adolescents. Journal Of Youth \& Adolescence, 41(8), 1008-1021. doi:10.1007/s10964-011-9730-y

Morrill, M. (2014). Sibling sexual abuse: An exploratory study of long-term consequences for self-esteem and counseling considerations. Journal Of Family Violence, 29(2), 205-213. doi:10.1007/s10896-013-9571-4

Nawaz, S. (2011). The relationship of parental and peer attachment bonds with the identity development during adolescence. FWU Journal Of Social Sciences, 5(1), 104-119

Obadina, S. (2013). Understanding attachment in abuse and neglect: implications for child development. British Journal Of School Nursing, 8(6), 290-295.

O'connor, B. P., \& Nikolic, J. (1990). Identity development and formal operations as sources of adolescent egocentrism. Journal Of Youth \& Adolescence, 19(2), 149158 . 
Orth, U., Robins, R., \& Widaman, K. (2012). Life-Span development of self-esteem and its effects on important life outcomes. Journal Of Personality And Social Psychology, 102(6), 1271-1288.

Pereda Beltran, N., Guilera Ferré, G., Forns, M., \& Gómez Benito, J. (2009). The international epidemiology of child sexual abuse: A continuation of Finkelhor. Child Abuse \& Neglect, 33, 331-342.

Pittman, J. F., Keiley, M. K., Kerpelman, J. L., Vaughn, B. E. (2011). Attachment, identity, and intimacy: Parallels between Bowlby's and Erikson's paradigms. Journal of Family Theory and Review, 32-46, DOI:10.1111/j.17562589.2010.00079.x

Purvis, K. B., Cross, D., R., \& Sunshine, W. L. (2007). The connected child. Chicago, IL: Mcgraw Hill.

Ratican, K. (1992) Sexual abuse survivors: Identifying symptoms and special treatment considerations. Journal of Counseling and Development, 71, 33-38.

Ratner, K. (2013). The role of parenting and attachment in identity style development. University Of Central Florida Undergraduate Research Journal, 7(1), 15-26.

Reese-Weber, M. \& Smith, D. (2011). Outcomes of sexual abuse as predictors of later sexual victimizations. Journal of Interpersonal Violence, 26, 1884 - 1905. DOI: $10.1177 / 0886260510372935$

Reid, J. A., Sullivan, C. J. (2009). A model of vulnerability for adult sexual victimization: The impact of attachment, child maltreatment, and scarred sexuality. Violence and Victims. 24(4), 485-501.

Rikhye, K., Turka, A. R., Kelly, M. M., Gange, G. G., Jr., Mello, A., F., Mello, M., F., et al. (2008). Interplay between childhood maltreatment, parental bonding, and gender effects: Impact on quality of life. Child Abuse and Neglect, 32, 19-34.

Roche, D., Runtz, M., \& Hunter, M. (1999). Adult attachment: A mediator between child sexual abuse and later psychological adjustment. Journal of Interpersonal Violence, 14(2), 184-207.

Rostad, W. L., Silverman, P., \& McDonald, M. K. (2014). Daddy's little girl goes to college: An investigation of females' perceived closeness with fathers and later risky behaviors. Journal Of American College Health, 62(4), 213-220. doi: $10.1080 / 07448481.2014 .887570$

Ruijten, T., Roelofs, J., \& Rood, L. (2011). The mediating role of rumination in the relation between quality of attachment relations and depressive symptoms in non- 
clinical adolescents. Journal Of Child \& Family Studies, 20(4), 452-459. doi:10.1007/s10826-010-9412-5

Sachs-Ericsson, N., Gayman, M., Kendall-Tackett, K., Lloyd, D., Medley, A., Collins, N., \& ... Sawyer, K. (2010). The long-term impact of childhood abuse on internalizing disorders among older adults: the moderating role of selfesteem. Aging \& Mental Health, 14(4), 489-501. doi:10.1080/13607860903191382

Schulte-Herbrüggen, O., Ahlers, C. J., Kronsbein, J., Ruumlter, A., Bahri, S., Vater, A., $\&$ Roepke, S. (2009). Impaired sexual function in patients with borderline personality disorder is determined by history of sexual abuse. Journal Of Sexual Medicine, 6(12), 3356-3363. doi:10.1111/j.1743-6109.2009.01422.x

Schultz, S. J. (1984). Family systems therapy: An integration. New York, NY: J. Aronson.

Seiffge-Krenke, I., \& Klessinger, N. (2009). Long-term effects of avoidant coping on adolescents' depressive symptoms. Journal Of Youth And Adolescence, 29(6), 617-630.

Shapiro, D., \& Levendosky, A. (1999). Adolescent survivors of childhood sexual abuse: The mediating role of attachment style and coping in psychological and interpersonal functioning. Child Abuse \& Neglect, 23(11), 1175-1191.

Simsek, O. (2013). Structural relations of personal and collective self-esteem to subjective well-being: Attachment as moderator. Social Indicators Research, 110(1), 219-236. doi:10.1007/s11205-011-9927-1

Steiger, A. E., Allemand, M., Robins, R. W., \& Fend, H. A. (2014). Low and decreasing self-esteem during adolescence predict adult depression two decades later. Journal Of Personality And Social Psychology, 106(2), 325-338. doi: $10.1037 / \mathrm{a} 0035133$

Smith, P. N., Gamble, S. A., Cort, N. A., Ward, E. A., Conwell, Y., \& Talbot, N. L. (2011). The relationships of attachment style and social maladjustment to death ideation in depressed women with a history of childhood sexual abuse. Journal of Clinical Psychology, 68(1), 78-87. doi:10.1002/jclp.20852

Schwartz, S., Beyers, W., Luyckx, K., Soenens, B., Zamboanga, B., Forthun, L., \& ... Waterman, A. (2011). Examining the light and dark sides of emerging adults' Identity: A study of identity status differences in positive and negative psychosocial functioning. Journal Of Youth \& Adolescence, 40(7), 839-859. doi:10.1007/s10964-010-9606-6 
Spielberger, C. D., Gorsuch, R. L., \& Lushene, R. E. (1970). Manual for the statetrait anxiety inventory. Palo Alto, CA: Consulting Psychologists Press.

Syed, M., Seiffge-Krenke, I. (2013). Personality development from adolescence to emerging adulthood: linking trajectories of ego development to the family context and identity formation. Journal of Personality and Social Psychology, 104(2), 371-384.

Walker, E., Holman, T., \& Busby, D. (2009). Childhood sexual abuse, other childhood factors, and pathways to survivors' adult relationship quality. Journal Of Family Violence, 24(6), 397-406. doi:10.1007/s10896-009-9242-7

Walker, M. D., Hernandez, A. M., \& Davey, M. (2012). Childhood sexual abuse and adult sexual identity formation: Intersection of gender, race, and sexual orientation. American Journal Of Family Therapy, 40(5), 385-398. doi:10.1080/01926187.2011.627318

Wenninger, K., \& Ehlers, A. (1998). Dysfunctional cognitions and adult psychological functioning in child sexual abuse survivors. Journal Of Traumatic Stress, 11(2), 281-300.

Yancey, C. C., Naufel, K., \& Hansen, D. (2013). The relationship of personal, family, and abuse-specific factors to children's clinical presentation following childhood sexual abuse. Journal Of Family Violence, 28(1), 31-42. doi:10.1007/s10896-0129485-6 
APPENDIX A

\section{INFORMED CONSENT: PHASE 1}

Illinois State University Department of Psychology

Principal Investigator: Dr. Marla Reese-Weber

PLEASE READ THIS DOCUMENT CAREFULLY. SIGN YOU NAME BELOW ONLY IF YOU AGREE TO PARTICIPATE. YOUR SIGNATURE IS REQUIRED FOR PARTICIPATION. YOU MUST BE 18 YEARS OF AGE TO PARTICIPATE. IF YOU DESIRE A COPY OF THIS CONSENT FORM, YOU MAY REQUEST ONE AND WE WILL PROVIDE IT.

"The policy of the Department of Psychology is that all research participation in the Department is voluntary, and you have the right to withdraw at any time, without prejudice, should you object to the nature of the research. Your responses are confidential. Any report of the data collected will be in summary form, without identifying individuals. You are entitled to ask questions and to receive an explanation after your participation. You will earn extra credit simply by coming to this appointment; you are free to withdraw your participation at any time without penalty. Alternative means of earning extra credit are available, for example brief writing assignments on magazine articles on psychology-related topics, or attending psychology-related community events. Please consult your instructor or class syllabus for information regarding alternative means of earning extra credit in your course."

If you have concerns about your participation in this study, you may contact:

Dr. Marla Reese-Weber (309) 438-5418

\section{Description of the Study:}

This study will ask you to complete a set of questionnaires.

\section{Nature of Participation:}

You will spend approximately 30 - 45 minutes completing the questionnaires.

\section{Purpose of the Study:}

You can be provided with an explanation of the study following the last phase of this study in December. If you are not selected for subsequent phases of this study, please contact Marla Reese-Weber at 438-5418 in December for a complete explanation. 
Possible Risks: When completing the questionnaires, you may come across a question or group of questions that you find unpleasant or upsetting. For instance, a few questions may cause you to think about painful past experiences and/or negative emotional states. You will be asked to provide confidential information about yourself, including information pertaining to past sexual experiences and drug use. In the event that you do become upset, a research assistant will remind you that you can withdraw from the study. Please remember you are free to skip specific questions and continue participating at no penalty. You are also free to withdraw this consent or stop participation.

\section{Possible Benefits:}

(1) If you are enrolled in a psychology course, you may be eligible to receive extra credit. You will receive extra credit simply by virtue of coming to your appointment; you are free to withdraw your participation at any time without penalty. Alternative means of earning extra credit are available, for example brief writing assignments on articles on psychology-related topics, or attending psychology-related community events. Please consult your instructor or class syllabus for information regarding alternative means of earning extra credit in your course.

(2) You are also eligible to enter your name into a random prize drawing for a $\$ 25$ Amazon gift card.

(3) When your participation is complete, you will be given an opportunity to learn about this research, which may be useful to understanding yourself and others.

(4) You will have an opportunity to contribute to psychological science by participating in this research study.

\section{Confidentiality:}

Your questionnaire packet has been assigned a code number that will protect your identity. All data will be kept in secured files, in accord with the standards of the University, Federal regulations, and the American Psychological Association. Finally, it is no individual person's responses that interest us; we are studying people in general.

\section{Opportunities to Question:}

Any technical questions about this research may be directed to Dr. Marla Reese-Weber at 438-5418. Any questions regarding your rights as a research participant or researchrelated injuries may be directed to ISU's Office of Research Ethics and Compliance (309) $438-2520$.

\section{Opportunities to Withdraw:}

If you decide now or at any point to withdraw this consent or stop participation, you are free to do so at no penalty to yourself. You are free to skip specific questions and continue participating at no penalty. 


\section{Opportunities to be Informed of Results:}

In all likelihood, the results will be fully available around the spring of 2015. If you wish to be told the results of this research, please contact Dr. Marla Reese-Weber at 438-5418. She will either meet with you to discuss the results or direct you to a copy of the results. In addition, there is a chance that the results from this study will be published in a scientific psychology journal, which would be available in many libraries. In such an article, participants would be identified in general terms such as "college students."

I am at least 18 years old and agree to participate.

Signature

Date

Print name here 


\section{APPENDIX B}

\section{DEMOGRAPHIC QUESTIONNAIRE}

Gender:

Male

Female

Other (e.g. transgender, gender queer), please specify

Sexual Orientation

Heterosexual

Homosexual/Gay/Lesbian

Bisexual

Pansexual

Other, please specify

Age:

Year in school

Freshman

Sophomore

Junior

Senior

Graduate-Master's

Graduate- Doctorate

Other, please specify

Ethnic Background:

White/Caucasian

Black/African-American

Hispanic/Latino

Asian-American

Middle Eastern/North African

Mixed Ethnicity

Prefer not to answer

Other, please specify: 
Current living arrangements

Live with parents

Live in the residence halls

Live in an apartment alone

Live in an apartment with friends

Live in an apartment with romantic partner

Other, please specify

Family Status:

Biological/adopted parents are currently married (skip next question)

Biological/adopted parents are currently divorced

Single Parent

Other, please specify

Following the divorce of your biological/adopted parents, with whom did you live the majority of the time?

Mother

Mother and Step-father

Father

Father and Step-mother

Other, please specify

Mother/stepmother's Highest Education:

Some high school, but no degree

High School degree

Two years college

Four years college (Bachelor's degree)

Graduate Degree (Master's degree or higher)

Father/stepfather's Highest Education:

Some high school, but no degree

High School degree

Two years college

Four years college (Bachelor's degree)

Graduate Degree (Master's degree or higher)

How many biological/adopted/step-siblings do you have? 


\section{APPENDIX C \\ DEBRIEFING STATEMENT}

If after completing this study you are upset or would like to discuss your interactions with others, you may contact the PATH crisis center for a referral at (309) 827-4005 or 1-800570-7284. You may also contact the Illinois State University Student Counseling Center at (309) 438-3655 or http://counseling.illinoisstate.edu/. Please remember that your responses are confidential and all data will be kept in secure files. If you have any questions regarding this study, please contact Dr. Marla Reese-Weber at (309) 438-5418. 